Thorax (1976), 31, 324.

\title{
Mitral valve reconstruction by posterior cusp advancement using a pericardial graft Long-term follow-up in nine patients
}

\author{
J . K E I T H R O S a nd E. G. J . O L S E N \\ Wessex Cardiac and Thoracic Centre, Southampton Western Hospital, Southampton \\ and Department of Pathology, National Heart Hospital, London
}

\begin{abstract}
Ross, J. K. and Olsen, E. G. J. (1976). Thorax, 31, 324-331. Mitral valve reconstruction by posterior cusp advancement using a pericardial graft: long-term follow-up in nine patients. Between December 1964 and March 1969, 11 posterior cusp advancement operations were carried out for patients with mitral valve disease in whom there was posterior cusp deficiency. Seven of the nine long-term survivors have required reoperation for recurrent mitral regurgitation, combined in six instances with stenosis of varying severity, the interval between the first and second operations ranging from five months to nine years (average 57.5 months). Histological examination of the pericardial grafts recovered at re-operation has been made and shows that after an initial period during which the graft retains near normal structure, there is a progressive degeneration with fibrous tissue replacement. This process takes place on both surfaces of the graft where there is evidence of vascularization in the zone between the graft remnant and the overlying and increasingly thick fibrous tissue covering.

The conclusion drawn from the experience with this small series is that the long-term performance of pericardial grafts designed to restore function to the posterior cusp of the mitral valve is poor and unpredictable.
\end{abstract}

When closed mitral valve surgery was developing in the $1950 \mathrm{~s}$, it soon became appreciated that mitral regurgitation due to rheumatic heart disease was often located posteriorly, and in some instances was due to selective involvement of the posterior cusp of the valve. Much ingenuity was applied to the treatment of mitral regurgitation by closed methods. Pericardial grafts were introduced in attempts to bolster the deficient retracted and fibrotic posterior cusp (Bailey et al., 1954; Vernejoul et al., 1960), to restrict the regurgitation in the region of the posterior commissure (Bolton et al., 1953; Bailey et al., 1954) or to control regurgitation by the 'flutter tamponade' principle (Bailey et al., 1951). None of these methods was successful, and when grafted tissue was recovered at necropsy it was found to have lost its flexibility and to have been converted into semi-rigid fibrous tissue, confirming results contained in the experimental laboratory (Moore and Shumacker, 1953).

The concept of cusp advancement was first introduced in animal experiments (Shumway and Lewis, 1954), but it was not until 1962 that
Sauvage and others described their experimentat and early clinical experience with pericardial autos grafts in the mitral valve introduced under direct. vision, followed soon afterwards by Frater et alo (1965). The technique was further developed, as applied to both the anterior and posterior cusps of the mitral valve, in 1966 (Sauvage and Wood 1966).

Theoretically the method had much to recomf mend it. First, in preserving the patient's own mitral valve and in the use of autogenous graft material, sound surgical principles were being apes plied to restore structure and function withoue the introduction of foreign material or of a prose thesis and therefore without the need for antie coagulant therapy. Secondly, in contrast to earlier? methods in which pericardium had been used this method ensured that the graft was subjecteop to a stress (stretch) which its structure and physicab properties might be expected to withstand. $\mathrm{Al}_{\square}^{\mathbb{\Phi}}$ though adaptation to the intracardiac environment to the extent of the graft retaining its microstruco ture seemed unlikely, it was reasonable to expect? 
that even if it were converted into fibrous tissue, this altered structure would not necessarily mean impairment of function as the grafted valve cusp would necessarily retain bulk in spite of predictable graft shrinkage. This shrinkage was anticipated by using grafts of generous size in the hope that this would restore and maintain an adequate closing surface for the opposing cusp to abut against.

This was the background against which pericardial cusp advancement in carefully selected cases was undertaken in the series here reported. It was considered a good alternative to prosthetic mitral valve replacement or conventional plication annuloplasty (Wooler et al., 1962).

\section{MATERIAL AND METHODS}

Between December 1964 and March 1969, posterior cusp advancement procedures were carried out in a total of 11 patients (Table I). All had severe valve disease with appropriate disability.

T A B L E I

MITRAL PERICARDIAL GRAFTS

\begin{tabular}{l|c}
\hline Diagnosis & No. \\
\hline Pure MR & 2 \\
MR, MS & 7 \\
Triple valve disease & 1 \\
MR, MS, AS, AR & 1 \\
\hline Total & 11 \\
\hline
\end{tabular}

AR-aortic regurgitation; AS-aortic stenosis; $M R$-mitral regurgitation; MS-mitral stenosis.

In the selection of patients, particular attention was paid to clinical and radiological evidence that the valve retained pliability and that it was not calcified. It was felt that residual mobility in the subvalve mechanism, with preservation of chordal length, was important if the technique was to succeed, and the final appraisal of this was made at surgery.

Two patients died at or soon after operation, one with triple valve disease and the other with a giant left atrium and mural calcification in whom there was important functional tricuspid regurgitation.

In all seven with associated mitral stenosis, a mitral valvotomy was performed before introducing the pericardial graft, and in the patient with associated aortic valve disease the aortic valve was replaced with a homograft.

OPERATIVE PROCEDURE Standard full-flow normothermic perfusion was used in all but three instances when moderate hypothermia was induced during bypass. A left lateral approach was used on seven, and a mid-line approach on four occasions. In all, a diamond-shaped pericardial graft, measuring approximately $10 \times 5 \mathrm{~cm}$, was taken before establishing extracorporeal circulation. Once the mitral valve had been exposed and assessed, valvotomy was undertaken if indicated. The posterior cusp was then detached from the annulus, the line of incision being taken just beyond the commissural angle at each end. The graft was then sutured into position, after rounding off its ends, using continuous sutures, usually locked in each corner and at the mid points on either side (Fig. 1). The exact size of graft (see Table II) depended on the size of the defect to be filled and the way the graft matched the edges of the defect as it was being sewn into position.

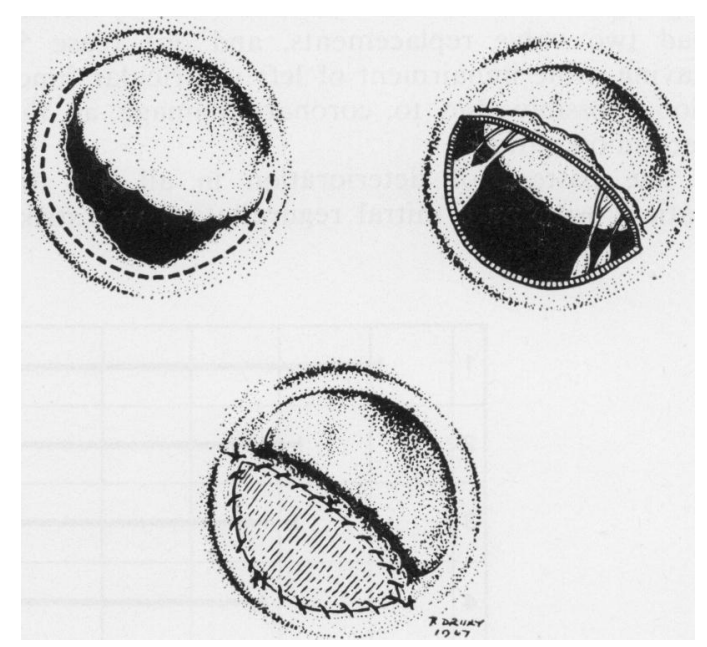

FIG. 1. Operative technique: The incision to detach the posterior cusp from the annulus is indicated by the interrupted line (top left). Into the resultant defect (top right) is sutured a diamond-or elliptical-shaped pericardial graft (below, centre).

In each case, once the repair was complete and bypass had been stopped, the valve was palpated and the result assessed. In case 9 , the valve was tested under direct vision with the heart beating and the aorta clamped (Ross, 1971) before aortic valve replacement. The results of this initial assessment of the amount of residual regurgitation are shown (Table II).

The operations were carried out at Harefield Hospital (6), the Middlesex Hospital (1), and the National Heart Hospital (4). 
T A B L E I I

MITRAL PERICARDIAL GRAFTS

\begin{tabular}{|c|c|c|c|c|c|c|}
\hline Case & Sex/Age & Operation Date & Graft Size (cm) & $\begin{array}{c}\text { Immediate } \\
\text { Result_-MR }\end{array}$ & Second Operation & Interval \\
\hline $\begin{array}{l}1 \\
2\end{array}$ & $\begin{array}{ll}F & 20 \\
M & 46\end{array}$ & $\begin{array}{l}10 \text { Dec '64 } \\
11 \text { Nov '65 }\end{array}$ & $\begin{array}{l}8 \times 3 \\
9 \times 4\end{array}$ & $\underset{0}{G r} 1$ & 18 Dec '73' & $\begin{array}{l}9 \text { yr } \\
5 \text { yr } 7 \mathrm{mth}\end{array}$ \\
\hline $\begin{array}{l}3 \\
4 \\
5 \\
6 \\
7 \\
8 \\
9\end{array}$ & $\begin{array}{ll}\mathbf{F} & 48 \\
\mathbf{F} & 23 \\
\mathbf{F} & \mathbf{4 0} \\
\mathbf{F} & 56 \\
\mathbf{F} & 29 \\
\mathbf{M} & \mathbf{2 6} \\
\mathbf{M} & \mathbf{6 0}\end{array}$ & $\begin{array}{r}4 \text { Nov '65 } \\
3 \text { Feb '66 } \\
9 \text { Nov '66 } \\
21 \text { Nov '67 } \\
12 \text { Mar '68 } \\
20 \text { Jun '68 } \\
27 \text { Mar '69 }\end{array}$ & $\begin{array}{c}7 \times 3.5 \\
10 \times 4 \\
5 \times 3 \\
11 \times 5 \cdot 5 \\
9.5 \times 5 \\
12 \times 7 \\
8 \times 3\end{array}$ & $\begin{array}{c}\text { Gr } 1 \\
0 \\
\text { Gr } 1 \\
\text { Gr } 2 \\
0 \\
\text { Gr } 2 \\
0\end{array}$ & $\begin{array}{l}27 \text { Jun '72' } \\
1 \text { Apr '71' } \\
18 \text { Mar '71 } \\
14 \text { Nov '68' } \\
26 \text { Sept '74 }\end{array}$ & $\begin{array}{l}6 \text { yr } 4 \text { mth } \\
4 \text { yr } 5 \text { mth } \\
3 \text { yr } 4 \text { mth } \\
5 \text { mth } \\
4 \text { yr } 6 \text { mth }\end{array}$ \\
\hline
\end{tabular}

${ }^{1}$ Histology.

LATE RESULTS All but two of the nine survivors have required re-operation for removal of the reconstructed valve with subsequent prosthetic or homograft replacement (see Fig. 2). One (case 2) died soon after his second operation; the remaining eight are alive and well, one (case 8) having had two valve replacements, and one (case 5) having some impairment of left ventricular function, possibly due to coronary damage at the second operation.

The pattern of deterioration in all but the patient with pure mitral regurgitation was strik- ingly similar in that they presented after at interval varying between six months and nine years with signs of combined mitral stenosis and progressively increasing mitral regurgitation. The severity of the mitral stenosis was more than could have been expected on the basis of inades quate valvotomy at the first operation. For example, mitral diastolic gradients of 12 ang $17 \mathrm{mmHg}$ were measured in cases 6 and 9 respec tively when the patients in question were re흥 investigated on deterioration after two and thre years' improvement.

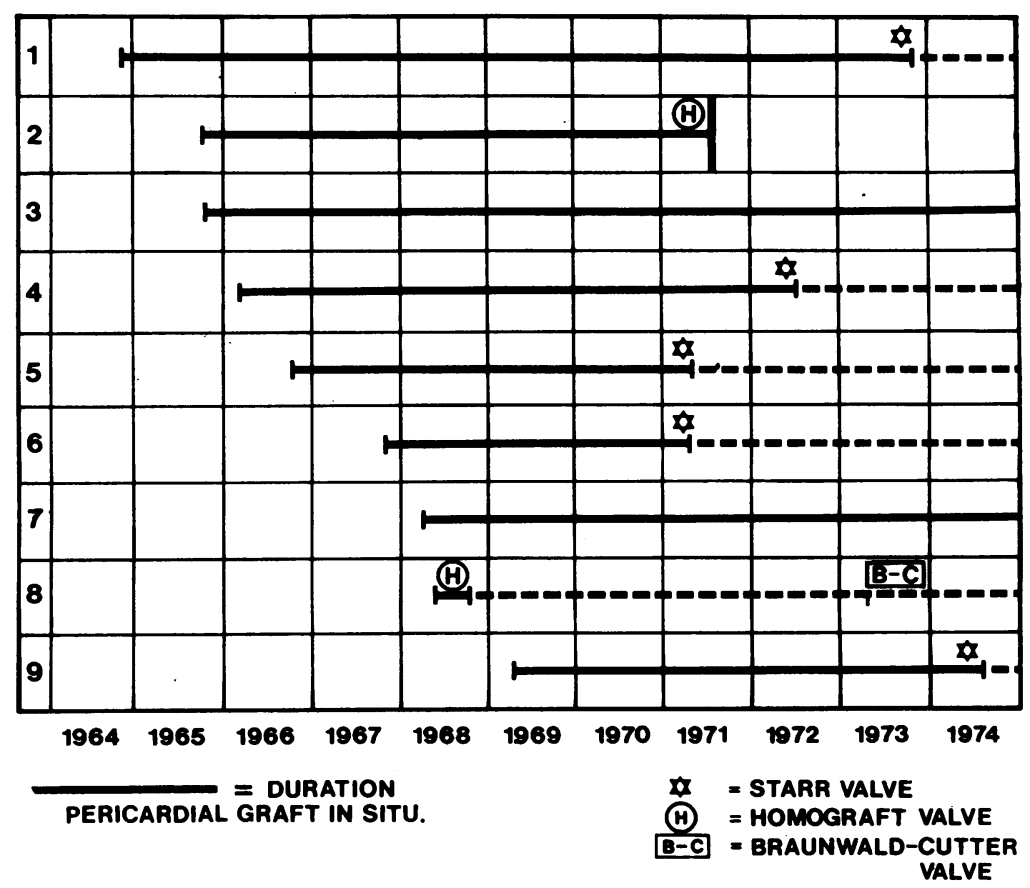

FIG. 2. Mitral valve posterior cusp advancement. 
ECHOCARDIOGRAPHY This has been carried out in two patients, one (case 7) six-and-a-half years after cusp advancement, and the other immediately before re-operation at five-and-a-quarter years (case 9). Both showed evidence of mitral stenosis (Fig. 3). In both instances, mitral stenosis had been completely relieved by open valvotomy before introduction of the pericardial graft at the original operation.

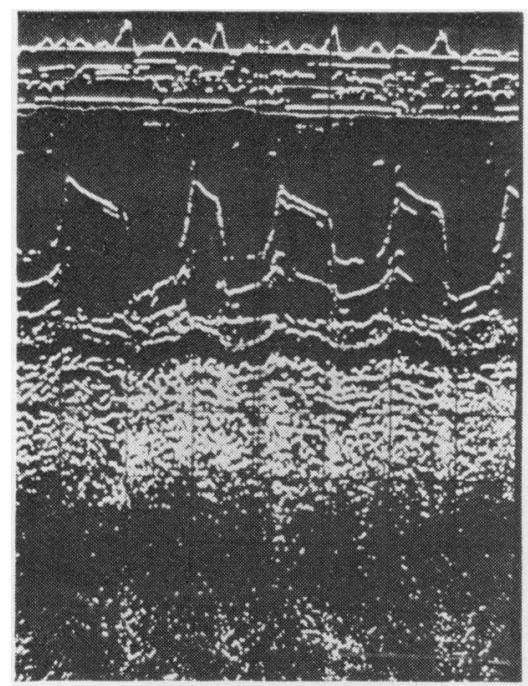

FIG. 3. Case 7. Six-and-a-half years after operation. Echocardiogram shows a slow diastolic closure rate, the posterior cusp moving in the same direction as the anterior cusp in diastole, ie, the appearances of mitral stenosis.

FINDINGS AT RE-OPERATION The gross appearance of the graft at the second operation has been varied. At five months (case 8) the graft was perfectly pliable, showed no thickening, and was the same size as when inserted. The original operation had failed because of severe disease affecting the subvalve mechanism, not appreciated fully at the time, and not because of changes in the graft.

Those grafts that had been in position for longer periods had all become thicker and, even if ballooned, more rigid (Fig. 4). The graft at nine years (case 1) was described as aneurysmal and myxomatous in appearance, and three (cases 2, 4 , and 9) had small defects in the annular suture line which undoubtedly contributed to the regurgitation present and might theoretically have given rise to diastolic murmurs. None was macroscopically calcified or showed signs of past infection,

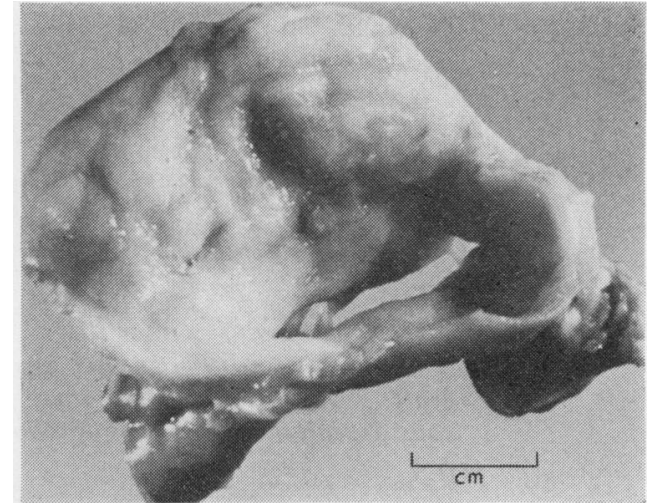

FIG. 4. Case 4. Resected mitral valve containing pericardial graft at six years four months. The pericardial graft (above) has a smooth but irregular surface and is thicker than the anterior cusp (below). The valve orifice is stenosed.

nor was there thrombus in relation to any of the grafts.

HISTOLOGY Seven of the reconstructed valves, replaced at Harefield Hospital, the National Heart Hospital and the Brompton Hospital, have been examined histologically. Areas selected for histology were blocked in paraffin, and subsequent 5-micron thick sections were stained with haematoxylin and eosin, Weigert's elastic van Gieson, and Martius scarlet blue (Lendrum et al., 1962).

The graft removed at five months (case 8) showed no thickening; there was preservation of its collagen but complete absence of nuclei. There were only small foci of early degenerative change and the graft was seen to be covered by an incomplete layer of fibrocytes (Figs 5 and 6).

The graft from case 4 at six years and four months showed considerable thickening and, in common with other long-term specimens examined, it was difficult to define the exact limits of the graft except by identifying pieces of suture material, around which there were foci of calcification. Both surfaces of the pericardial graft were found to be covered by dense, regularly arranged collagen tissue with a normal complement of nuclei. The pericardial remnant was easily identified and showed some preservation of collagen but marked degeneration in other areas. In the intermediate zone between the graft and its fibrous tissue covering lay many small blood vessels (Fig. 7).

At nine years (case 1) the grafted area showed considerable thickening due to superimposed colla- 


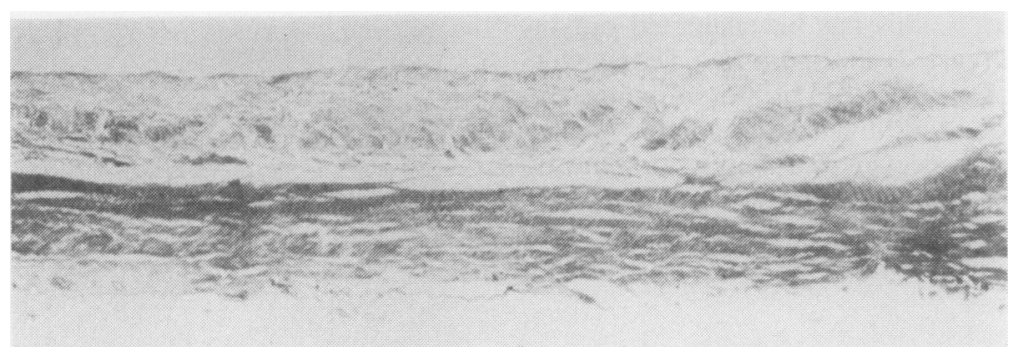

FIG. 5. Case 8. Pericardial graft at five months. The structure of the graft is well preserved but there are no nuclei present. There is no signifcant deposition of surface fibrous tissue $(H$ and $E \times 40)$.

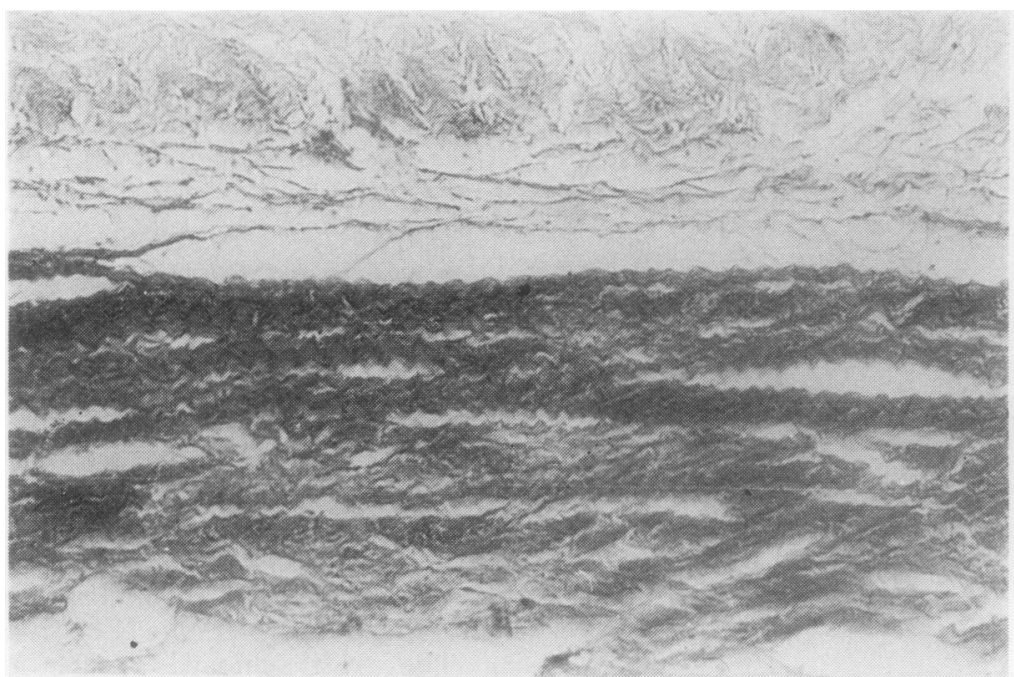

FIG. 6. Case 8. Pericardial graft at five months at higher magnification. Section shows well preserved collagen architecture and confirms the absence of nuclei ( $H$ and $E \times 240)$.

gen tissue containing some fibroblastic nuclei. In the graft itself there was widespread degenerative change with eosinophilic, structureless material and a total absence of nuclei. This represents the near end-stage of granulation tissue replacement of the degenerate pericardial graft.

The histological appearances of the other grafts which had been in situ for between four and six years all showed various stages of graft degeneration and fibrous tissue replacement. None showed any microscopic evidence of bacterial infection or florid surface thrombus, and focal calcification was confined to the region of suture material.

\section{DISCUSSION}

The clinical pattern of deterioration with recurrent stenosis and regurgitation is interesting and agrees with the experience of Van der Spuy (1972), in whose series of 20 pericardial cusp as vancements there were 13 long-term survivors Six of these required re-operation, four for pro: gressive mixed stenosis and regurgitation, one fon progressive stenosis, and one for progressive ino competence of the reconstructed valve. Van de Spuy noted that late deterioration was unrelateg to the efficacy of the pericardial repair as judgeg by palpation at the time of the first operatiof. This observation is also true for the present series in which seven requiring re-operation includeg three in whom an apparently perfect initial resudt had been achieved. One of the two patients whip still has a pericardial graft (case 3) had some ro sidual regurgitation, but judged on clinicâ grounds (re-investigation refused), this regurgitation has remained for over nine years. 


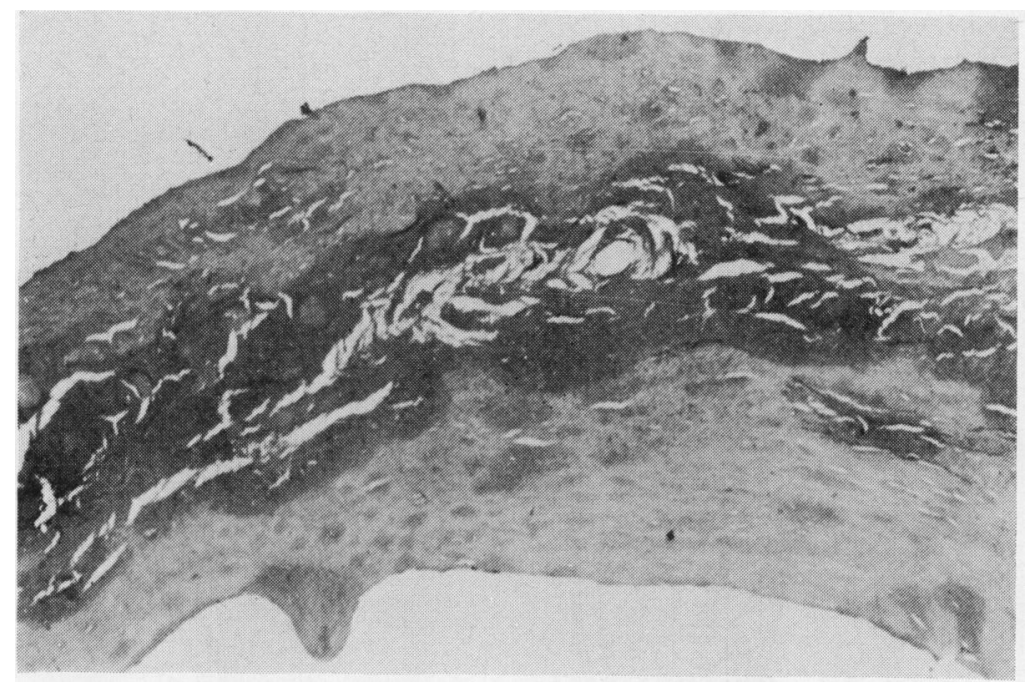

FIG. 7. Case 4. Pericardial graft at six-and-a-half years. The structureless remains of the pericardial graft are easily identified with mature fibrous tissue on both its upper and lower surfaces $(H$ and $E \times 40)$.

At re-operation there was no clear evidence that the grafts themselves had been responsible for causing obstruction to the mitral orifice, but it is conceivable that the graft, in bulging towards the ventricle in diastole, might hold the orifice partly closed by displacing the free edge of the posterior cusp towards its fellow. If this were the explanation it might be expected that the more mobile and larger the graft, the more definite the signs of mitral obstruction should be, and that this finding should therefore be most obvious soon after operation. This has happened in one case (Watson, 1967), but although some of the patients in this series had diastolic murmurs audible soon after surgery, they tended to be short, the signs of important stenosis being a late development.

Whatever the explanation for the stenosis, its occurrence has to be recorded as a consistent disadvantage of the technique. The possibility that, in the valve as a whole, progression of the rheumatic process contributes to this picture cannot be excluded.

The reappearance of regurgitation is easier to understand as the success of the technique depends on graft mobility and the depth of closing surface which the graft provides (Fig. 8). This fact is easy to appreciate on palpation of the valve immediately after repair when, in systole, the ballooning graft (and not the free edge of the posterior cusp) meets the anterior leaflet to close the valve.

As the graft shrinks by approximately one-third and becomes stiffer this closing mechanism is lost. The only conclusion that can be drawn from the evidence in this series is that, in spite of the increased posterior cusp bulk provided by the graft, it is not sufficient or it is in the wrong place for the anterior cusp to close against.

Histologically, the reason for the increase in the thickness of the grafts was seen to be the deposition of fibrous tissue on both the atrial and ventricular surfaces of the graft. This was not evident in the graft recovered at five months, but obvious in those that had been in place for four years or more. There was no evidence of host reaction at the interface between the cusp tissue and the graft, and in the later specimens the junction could not be clearly identified except by the presence of suture material. The presence of blood vessels in the zone between the graft and the overlying fibrous tissue layer, also reported by Sauvage et al. (1966), suggests that an active process of granulation tissue replacement is responsible for the gradual conversion of the graft into fibrous tissue, and that this process is, in turn, responsible for the increase in thickness of the graft. This may be augmented by the organization of surface fibrin deposits as described by Tweedy (1956) in rheumatic heart disease.

Finally, although the series described is small, the fact that only two of nine long-term survivors still retain acceptable mitral valve function with their pericardial grafts in situ is taken to indicate 


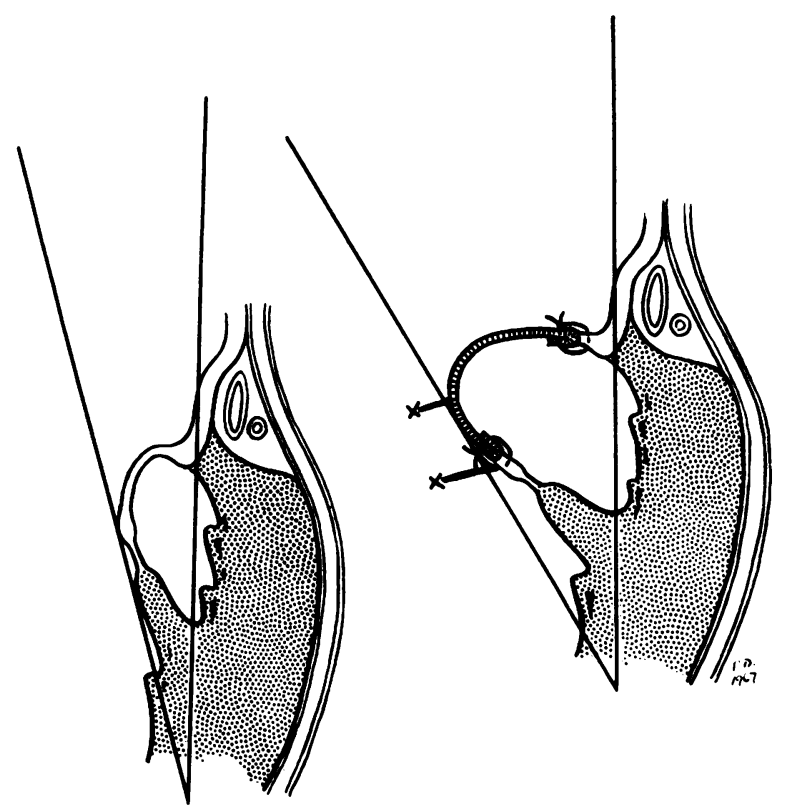

FIG. 8. Semidiagrammatic representation of the mitral posterior cusp to show how the introduction of the pericardial graft allows the posterior cusp mechanism to move through a wider arc. The drawing also shows how the graft, stretched in systole, offers depth of closing surface (between $x$ and $x$ ) to the opposing anterior cusp. Both mobility and depth of closing surface are lost with the changes that occur in the grafts with the passage of time.

that the technique cannot be recommended for the treatment of mitral regurgitation due to posterior cusp deficiency, or so-called mural cusp disease.

We are grateful to Dr. Walter Somerville, Dr. R. W. Emanuel, and Dr. M. J. Goldberg for permission to publish their cases, and to Mr. W. P. Cleland and Mr. M. H. Yacoub for their accounts of second operations (cases 1, 2, and 9); also to Dr. K. F. W. Hinson, of the Brompton Hospital, and Dr. M. H. Bennett, of Harefield and Mount Vernon Hospitals, Northwood, for their help in providing valve specimens for inclusion in this study.

\section{REFERENCES}

Bailey, C. P., Jamison, W. L., Bakst, A. E., Bolton, H. E., Nichols, H. T., and Gemeinhardt, W. (1954). The surgical correction of mitral insufficiency by the use of pericardial grafts. Journal of Thoracic Surgery, 28, 551.

O’Neill, T. J. E., Glover, R. P., Jamison, W. L., and Redondo-Ramirez, H. P. (1951). Surgical re- pair of mitral insufficiency (preliminary report). Diseases of the Chest, 19, 125.

Bolton, H. E., Bailey, C. P., Jamison, W. L., andi Rao, K. V. S. (1953). Multivalvular heart disease and simultaneous surgical correction. Journal of the International College of Surgeons, 20, 1.

Frater, R. W. M., Berghuis, J., Brown, A. L. Jr., and Ellis, F. H. Jr. (1965). The experimental and clinical use of autogenous pericardium for the replacement and extension of mitral and tricuspids valve cusps and chordae. Journal of Cardion vascular Surgery, 6, 214.

Lendrum, A. C., Fraser, D. S., Slidders, W., and Henderson, R. (1962). Studies on the character and staining of fibrin. Journal of Clinical Patheo ology, 15, 401.

Moore, T. C. and Shumacker, H. B. Jr. (1953). Un suitability of transventricular autogenous slings for diminishing valvular insufficiency. Surgery, $33, \overline{0}$ 173.

Ross, J. K. (1971). Assessment of mitral valve func- $\frac{\rho}{\Phi}$ tion at operation and the prevention of systemice embolism. Thorax, 26, 306.

Sauvage, L. G. and Wood, S. J. (1966). Techniquen for correction of mitral insufficiency by leaflet 
advancement. Journal of Thoracic and Cardiovascular Surgery, 51, 649.

Berger, K. E., and Campbell, A. A. (1966). Autologous pericardium for mitral leaflet advancement. Findings in the human after 56 months. Journal of Thoracic and Cardiovascular Surgery, 52, 849.

- B Bill, A. H. Jr., and Logan, G. A. (1962). Pericardial autografts in the mitral valve. Journal of Thoracic and Cardiovascular Surgery, 44, 67.

Shumway, N. E. and Lewis, F. J. (1954). Experimental surgery of the mitral valve under direct vision using hypothermia. Surgical Forum, 5, 12.

Tweedy, P. S. (1956). The pathogenesis of valvular thickening in rheumatic heart disease. British Heart Journal, 18, 173.

Van der Spuy, J. C. (1972). Mitral valve pericardio- plasty-a long-term follow-up study. Thorax, 27, 207.

Vernejoul, R. de, Henry, E., Courbier, R., Torresani, J., Monties, J. R., Imbert, P., and Garabedian, B. (1960). Surgical treatment of mitral insufficiency by pericardial plastic repair: experimental research. (French). A nnals de Chirurgerie, 14, 989.

Watson, D. A. (1967). Personal communication.

Wooler, G. H., Nixon, P. G. F., Grimshaw, V. A., and Watson, D. A. (1962). Experiences with the repair of the mitral valve in mitral incompetence. Thorax, 17, 49.

Requests for reprints to: J. K. Ross, MS, FRCS, Wessex Cardiac and Thoracic Centre, Scuthampton Western Hospital, Oakley Road, Southampton SO9 4WQ. 